\title{
BENEFICIAL EFFECTS OF BOTULINUM TOXIN TYPE A IN TRIGEMINAL NEURALGIA
}

\author{
Carlos Zúñiga, Sergio Díaz, Fabián Piedimonte, Federico Micheli
}

\begin{abstract}
Botulinum toxin has been thoroughly studied as a potential tool in the treatment of several pain syndromes. Therefore, we assessed the clinical effects of botulinum toxin type A injections in 12 patients with otherwise unresponsive idiopathic trigeminal neuralgia. Patients were infiltrated with 20-50 units of botulinum toxin in trigger zones. Those who presented with mandibular involvement were also infiltrated in the masseter muscle. The patients were assessed on a weekly basis using the Visual Analogic Scale for pain. Ten of our patients reported a significant benefit from botulinum toxin injections, with reduction or even disappearance of pain, and remained pain free for as long as 60 days. Our findings suggest that botulinum toxin may represent a useful therapeutic tool in the management of patients with this entity.
\end{abstract}

KEY WORDS: trigeminal neuralgia, botulinum toxin, facial pain.

\section{Beneficio de la toxina botulínica tipo $A$ en neuralgia del trigemino}

Resumen - La toxina botulínica ha sido estudiada en forma exhaustiva como una potencial herramienta en el tratamiento de múltiples síndromes dolorosos. Por lo tanto, evaluamos los efectos clínicos de la aplicación de toxina botulínica tipo $\mathrm{A}$ en 12 sujetos con neuralgia trigeminal idiopática resistente a manejo farmacológico. Se aplicaron en dichos sujetos entre 20 y 50 unidades de toxina botulínica tipo A en las zonas gatillo. Además se infiltró el músculo masetero en aquellos que presentaban involucro mandibular. Los sujetos fueron evaluados semanalmente con una escala visual análoga para dolor. Diez de los sujetos reportaron un beneficio significativo con el uso de toxina botulínica, con reducción e incluso desaparición del dolor, permaneciendo libres de dolor por un periodo de hasta 60 días. Nuestros hallazgos sugieren que la toxina botulínica puede representar una herramienta terapéutica útil en el manejo de pacientes con esta entidad.

PALABRAS-CLAVE: neuralgia trigeminal, toxina botulínica, dolor facial.

Trigeminal neuralgia (TN) is characterized by recurrent episodes of severe, excruciating lancinating pain localized to small areas of the face. It affects $\sim 4.5$ per 100,000 of the general population ${ }^{1,2}$, with onset usually in middle or old age; however, young adults, mainly those with multiple sclerosis, and even children may be affected. Attacks, usually lasting a few seconds, may occur repeatedly within a short period of time. They are often precipitated by mild sensory stimulation of so-called trigger zones, which may be located anywhere within the territory of the affected trigeminal nerve.

Multiple factors are associated with trigeminal neuralgia including aging, multiple sclerosis, persistent viral infection of the trigeminal ganglion, as well as structural abnormalities compressing the ganglion (arterial or venous loops, tumors such as meningiomas, and cysts such as epidermoids). However, there is increasing evidence support- ing that most cases are due to focal compression of the root entry zone of the fifth nerve at the pons by an aberrant arterial or venous loop $p^{3,4}$, leading to demyelination of trigeminal sensory fibers within either the nerve root or, less commonly, the brainstem.

Encouraged by our findings in a patient with both hemifacial spasm and TN in whom botulinum toxin (BT) was able to control both spasms and pain ${ }^{5}$, we treated 12 further patients with idiopathic TN, but no hemifacial spasm, to evaluate the analgesic effects of BT in the management of this disorder.

\section{METHOD}

Twelve patients with idiopathic TN, 5 males and 7 females, ages ranging from 28 to 91 years (mean age: 58.5 years) were included (Table). The mean duration of disease was 6.2 years (range 6 months to 12 years). Pain affected the maxillary root in 6 cas-

Parkinson's Disease and Movement Disorders Unit, Hospital de Clínicas “José de San Martín”, Buenos Aires, Argentina.

Received 21 January 2008, received in final form 24 April 2008. Accepted 19 May 2008.

Dr. Carlos Zúñiga - Ave. Tepeyac \#1287, Col. Chapalita. C.P. 45040. Zapopan, Jalisco, México. E-mail: c_zuniga_ramirez@yahoo.com 
Table. Clinical and demographic features of 12 patients with trigeminal neuralgia.

\begin{tabular}{ccccccc}
\hline Patient & Gender & Age (years) & Onset & Trigger zone & Branch & Neurological exam \\
\hline 1 & F & 63 & 1994 & Right infraorbital & Right V1, V2 & Normal \\
2 & F & 28 & 2003 & Right pretragus & Right V2 & Normal \\
3 & M & 41 & 2002 & Left infraorbital & Left V2 & Lacrymation \\
4 & F & 64 & 1992 & Left infraorbital & Left V1, V2 & Normal \\
5 & M & 70 & 1996 & Right nostril, upper lip & Right V2 & Normal \\
6 & F & 42 & 1999 & Right nostril, mouth angle & Right V1, V2 & Right painful tic \\
7 & M & 80 & 2001 & Right eyebrow, infraorbital & Right V1, V2 & Normal \\
8 & M & 69 & 1992 & Left upper lip & Left V2 & Normal \\
9 & F & 91 & 1994 & Right nostril, upper lip & Right V2, V3 & Normal \\
10 & F & 53 & 1998 & Right upper dental arch & Right V2 & Normal \\
11 & M & 54 & 1995 & Left upper lip & Left V2, V3 & Sensory loss in V1, V2, V3 (left) \\
12 & F & 47 & 2002 & Left upper lip & Left V2 & Normal \\
\hline
\end{tabular}

es, whereas maxillary and mandibular roots were involved in 2 cases, and ophthalmic and maxillary roots, in 4 cases. Four cases presented left side involvement; eight cases, right side involvement. In all patients pain could be elicited by mild sensory stimulation in distinct skin areas, consistent with trigger zones that were marked in some cases as in order to prevent patients from shaving, kissing or washing their faces for fear of triggering unbearable pain. All patients had been treated with drugs known to improve TN, with little effect on pain relief, if any, and had been considered candidates for surgery. Previous medication remained unchanged. Currently, 9 patients were on carbamazepine (400 to 1,200 mg), 2 on oxcarbazepine ( 600 to 1,200 mg), for at least 3 months, whereas one received no treatment. This regimen had been maintained for the last 3 months. Four patients had undergone previous surgical treatment. The MRI results were normal throughout the testing.

After their inclusion in this open label study by signing in an informed consent form, botulinum toxin type $A$ (Botox ${ }^{\circledR}$ ) was injected subcutaneously in the painful area, especially in the trigger zones. In patients with mandibular root involvement, a larger dose of the toxin was injected in the masseter in order to avoid undesired cosmetic effects. The population was evaluated weekly for 8 weeks by using the visual analogic scale (VAS). The number of painful paroxysms was also considered.

\section{RESULTS}

In 10 patients, BT injection was followed by pain relief, after some minutes. The trigger zones completely disappeared within the first 2 weeks after the injection, and the skin area could be readily stimulated without triggering any discomfort. The cumulative mean VAS scores were 8.83 (SD: 1.19) at baseline and 4.08 (SD: 4.44) at week 8 , whereas the mean cumulative number of paroxysms was 23.42 (SD: 13.5) at baseline and 8.67 (SD: 12.4) at week 8. Higher doses of botulinum toxin type A correlated with a faster onset of pain relief. However, two patients, cases 2 and 6, failed to respond. Doses of botulinum toxin ranged from 20 to $50 \mathrm{U}$. Additional injections in 2 cases (cases 1 and 4) led to similar results. Transient facial asymmetry, present in one case, was the only side effect. To illustrate our findings two cases are described in detail.

\section{Patient 1}

A 63-year-old female presented in 1994 after a tooth removal (right lower premolar) with severe paroxysmal pain, which she described as an electric shock, in the right hemifacial area, mainly involving the territory of the right ophthalmic branch. The trigger point was located in the right infraorbital region. Neurological examination was normal. A brain MRI with contrast enhancement was normal. Carbamazepine (up to $600 \mathrm{mg} /$ day) was prescribed. Some improvement was observed until the beginning of early this year when due to both worsening of pain severity and an increase in the number of painful attacks, medication was increased to $1,200 \mathrm{mg} /$ day. As no response was observed, medication was discontinued a week ago. For the last 10 days she has experienced severe pain with over 35 paroxysms every 24 hours. Pain was severe during the last week, as evaluated with the VAS. Thirty-five units of botulinum toxin type $A$ (Botox ${ }^{\circledR}$ ) were injected in the right frontotemporal area. The results obtained are as follows: baseline VAS evaluation: 9 points. Evaluation at 1 week post-injection: VAS: 3 points, without paroxysms. Evaluation at 15 days post-injection: VAS: 0 points, without paroxysms. Evaluation at 8 week post-injection: VAS: 0 points, without paroxysms.

\section{Patient 4}

A 64-year-old female presented 12 years ago with paroxysmal pain, which she described as an electric discharge 
in the region of the first and second branches of the left fifth cranial nerve, with a trigger point in the left infraorbital area. She had been initially treated with carbamazepine ( $600 \mathrm{mg} /$ day) with moderate improvement until this year, when paroxysmal episodes and pain intensity increased. Carbamazepine was increased to $1,000 \mathrm{mg} /$ day; however, no response was observed. The neurological examination was normal, as also was a brain MRI. The VAS score was 10 points during the last month with 30 to 40 paroxysms per day, and persistent pain in-between. Forty units of botulinum toxin type $A\left(\right.$ Botox $^{\circledR}$ ) were injected subcutaneously into the left frontotemporal area, while 5 units were administered subcutaneously in the zygomatic area, and 5 more units in the peribuccal area (upper lip). At 24 hours post-infiltration the paroxysms had disappeared. VAS: 0 points. The improvement persisted for 70 days (without pain); however, moderate pain gradually reappeared (VAS: 3 points) during the last week (week 12) but without paroxysms. At 90 days new injections were performed in the same points and at the same doses followed by an evaluation a week later. A significant improvement (without pain and without paroxysms, VAS: 0 points) was observed after the second infiltration.

\section{DISCUSSION}

Our findings demonstrate the beneficial effects of BT in pain control in cases of idiopathic TN, which supports our previous findings ${ }^{5}$ as well as those by Piovesan et al. ${ }^{6}$ and Borodic and Acquadro ${ }^{7}$. However, many aspects remain unclear including the extremely rapid action of pain control by the toxin, within minutes of the injection, in some of our cases. On the other hand, in most of our patients pain recurred after 60 days in contrast to the motor benefit usually lasting between 3 and 6 months depending both on an individual basis and the underlying cause of muscle hyperactivity. However, in other patients pain relief lasted up to three months.

Botulinum toxin type A has repeatedly shown its efficacy for the treatment of headache in several clinical trials, but there still is uncertainty as to how botulinum toxin type A should be optimally used for treating headache, and which patients are best suited for this treatment ${ }^{8,9}$. In addition, myofacial pain syndrome ${ }^{10}$, neuropathic pain disorders $^{11}$, fibromyalgia ${ }^{12}$, chronic idiopathic anal pain ${ }^{13}$, and "off" painful dystonia in Parkinson's disease ${ }^{14}$, among others, have also been reported to respond to BT injections.

Initially, we described a patient with a painful tic convulsive in whom BT injections to relieve muscle twitching markedly improved pain ${ }^{5}$. Borodic and Acquadro reported 11 cases of patients with TN, otherwise unresponsive to at least 3 drugs, treated with BT injections (Botox ${ }^{\circledR}$ ) with doses ranging from 25 to $75 \mathrm{U}$. Eight out of eleven responded to treatment with a benefit duration ranging from 2 to 4 months. Injections were performed $10 \mathrm{~mm}$ apart to cover the painful anatomic region. The depth of the injection varied from 1 to $3 \mathrm{~mm}$.

Piovesan et al. ${ }^{6}$ reported thirteen patients with TN treated with botulinum toxin type A injected transcutaneously among the trigeminal branches. All patients had benefit from this treatment, reducing significantly the visual analog scale pain score. Peak effect was reached 20 days after injection, lasting for more than 60 days in all patients. Four patients treated previously with oral medication became medication free, while the others reduced their consumption by more than $50 \%$.

Our 12 patients with $\mathrm{TN}$ received $\mathrm{BT}$ in a relatively different pattern as regards both doses and areas of injection as compared to Borodic ${ }^{7}$ and Piovesan et al. patterns ${ }^{6}$, and although most cases responded favorably, the onset of benefit and duration of response were quite dissimilar among them.

The pathophysiology of TN has been much debated; the pain being ascribed variously to hyperactivity or abnormal discharges arising from the gasserian ganglion, the 'injured' nerve root and the trigeminal nucleus within the brainstem ${ }^{15}$. Although some aspects of TN pathogenesis remain unclear, it is recognized that ephaptic cross-talk between fibers mediating light touch and those involved in the generation of pain may account for the precipitation of neuralgia attacks by light tactile stimulation of facial trigger zones.

It has been proposed that a variety of facial pain syndromes are sequential stages of the same disease process. Typical trigeminal neuralgia caused by microvascular compression of the trigeminal nerve root in the posterior fossa would become over time an atypical trigeminal neuralgia, if untreated. This transformation involves changes in the nature of pain and development of sensory impairment. Should this theory prove in fact correct, trigeminal neuralgia, atypical neuralgia, and trigeminal neuropathic pain would represent different degrees of injury to the trigeminal nerve, therefore comprising a continuous spectrum rather than discrete diagnoses ${ }^{16}$.

Several mechanisms have been advanced to explain the analgesic properties ascribed to BT. Apart from its effect on muscle contraction because of its binding to the presynaptic nerve terminal, inhibiting the release of acetylcholine (ACh), a direct analgesic action has already been recognized, suggesting that $B T$ has alternative modes of action ${ }^{17}$. Most hypotheses rest on the assumption that BT inhibits not only the exocytosis of ACh but also of other neurotransmitters. Such an action could be analgesic if the release of neuropeptides from nociceptive nerve end- 
ings were prevented. Another site of an analgesic action could be the postganglionic sympathetic nerve ending that uses norepinephrine and ATP as transmitters. Norepinephrine is known to increase cases of chronic pain, and ATP is a stimulant of muscle nociceptors. If BT inhibits the release of these transmitters, it can then be analgesic in cases of sympathetically maintained pain including the complex regional pain syndrome ${ }^{18}$.

Our cases suggest that BT could be a useful therapeutic tool in the management of both TN and probably other similar conditions. BT provides a very fast and long-lasting benefit, and is otherwise devoid of systemic side effects. Further double-blind studies including an appropriate number of patients are required to validate our findings and to explore whether higher doses provide a more sustained effect and optimize injection sites.

\section{REFERENCES}

1. Yoshimasu F, Kurland LT, Elveback LR. Tic douloureaux in Rochester, Minnesota, 1945-1969. Neurology 1972;22:952-956.

2. Katusic S, Williams DB, Beard CM, Bergstralh EJ, Kurland LT. Epidemiology and clinical features of idiopathic trigeminal neuralgia and glossopharyngeal neuralgia: similarities and differences, Rochester, Minnesota, 1945-1984. Neuroepidemiology 1991;10:276-281.

3. Hilton DA, Love S, Gradidge T, Coakham HB. Pathological findings associated with trigeminal neuralgia caused by vascular compression. Neurosurgery 1994;35:299-303.
4. Bowsher D. Trigeminal neuralgia: an anatomically oriented review. Clin Anat 1997;10:409-415.

5. Micheli F, Scorticati MC, Raina G. Beneficial effects of botulinum toxin type a for patients with painful tic convulsif. Clin Neuropharmacol 2002;25:260-262.

6. Piovesan EJ, Teive HG, Kowacs PA, Della Coletta MV, Werneck LC, Silberstein SD. An open study of botulinum-A toxin treatment of trigeminal neuralgia. Neurology 2005;65:1306-1308.

7. Borodic GE, Acquadro MA. The use of botulinum toxin for the treatment of chronic facial pain. J Pain 2002;3:21-27.

8. Blumenfeld A. Botulinum toxin type A as an effective prophylactic treatment in primary headache disorders. Headache 2003;43:853-860.

9. Silberstein S, Mathew N, Saper J, Jenkins S. Botulinum toxin type A as a migraine preventive treatment. For the BOTOX Migraine Clinical Research Group. Headache 2000;40:445-450.

10. Cheshire WP, Abashian SW, Mann JD. Botulinum toxin in the treatment of myofacial pain syndrome. Pain 1994;59:65-69.

11. Argoff CE. A focused review on the use of botulinum toxins for neuropathic pain. Clin J Pain 2002;18(Suppl 6):S177-S181.

12. Smith HS, Audette J, Royal MA. Botulinum toxin in pain management of soft tissue syndromes. Clin J Pain 2002;18(Suppl 6):S147-S154.

13. Christiansen J, Bruun E, Skjoldbye B, Hagen K. Chronic idiopathic anal pain: analysis of ultrasonography, pathology, and treatment. Dis Colon Rectum 2001;44:661-665.

14. Pacchetti C, Albani G, Martignoni E, Godi L, Alfonsi E, Nappi G. "Off" painful dystonia in Parkinson's disease treated with botulinum toxin Mov Disord 1995;10:333-336.

15. Love S, Coakham HB. Trigeminal neuralgia: pathology and pathogenesis. Brain 2001;124:2347-2360.

16. Burchiel KJ, Slavin KV. On the natural history of trigeminal neuralgia. Neurosurgery 2000;46:152-155.

17. Klein AW. The therapeutic potential of botulinum toxin. Dermatol Surg 2004;30:452-455.

18. Mense S. Neurobiological basis for the use of botulinum toxin in pain therapy. J Neurol 2004;251(Suppl 1):S1-S7. 